\title{
Emakoiden fosforinerityksen vähentäminen rehun fosforipitoisuutta alentamalla
}

\author{
Liisa Keto ${ }^{1)}$, Sini Perttilä2), Heidi Högel ${ }^{1)}$, Timo Heikkilä ${ }^{3)}$, Satu Valkama ${ }^{4)}$ \\ 1)Luonnonvarakeskus,Tietotie2 C,31600Jokioinen, liisa.keto@luke.fi,heidi.hogel@luke.fi \\ 2)Luonnonvarakeskus, Latokartanonkaari 9,007901 Helsinki, sini.perttila@luke.fi \\ 3) Heikkilän tila, Liukolantie 334,21290Rusko,timo@heikkilantila.com \\ 4)Hankkija Oy,Peltokuumolantie 4,05800 Hyvinkää, satu.valkama@hankkija.fi
}

\section{TIIVISTELMÄ}

SiFos-hankkeessa tavoiteltiin sikojen ja siipikarjan ruokinnan kehittämisellä mm. maatilojen typpi- ja fosforierityksen minimointia. Lisäksi tavoiteltiin tilatason laskentatyökaluja, joiden avulla viljelijä voi tarkentaa tilansa ravinnekiertoa rehusta lantaan ja pellon kautta takaisin rehuun. Tässä SiFos-hankkeen osassa keskityttiin emakoiden tiineydenaikaisen fosforinerityksen vähentämisen keinoihin.

Tilaseuranta toteutettiin varsinaissuomalaisella porsastuotantotilalla yhteistyössä rehu- ja lihateollisuuden kanssa. Kontrollikäsittelyssä emakoiden rehustus oli tilan tavanomainen rehustus (alkutilanne), josta tehtiin alkutilanneanalyysi analysoimalla tiineiden ja imettävien emakoiden rehu-, sonta-, virtsa- ja luunäytteitä. Alkutilanneanalyysiä varten yhteensä 166 emakolta otettiin sonta- ja virtsanäytteitä satunnaisesti kolmessa eri tiineyden vaiheessa. Lisäksi noin 100 teuraaksi menneestä emakosta kerättiin luunäytteitä analysoitavaksi ennen ja jälkeen rehumuutoksen. Mahdollisimman monelta emakolta kerättiin molemmat eritenäytteet. Koekäsittelyssä tiineiden emakoiden rehun kokonaisfosforipitoisuutta alennettiin. Eläinten riittävästä fosforinsaannista huolehdittiin siten, että rehujen sulavan fosforin laskennallinen pitoisuus pidettiin riittävän korkeana ja fosforin hyväksikäyttö varmistettiin oikealla fytaasientsyymiannoksella. Entsyymin tarkoitus on irrottaa rehuaineiden fytaattifosforia sian elimistön käyttöön. Koekäsittelyyn valittujen 52 emakon tiineyden aikana niiltä kerättiin sonta- ja virtsanäytteet tiineyden päivinä n. 30, 90 ja 103-114 tilan tuotantorytmiin sovittaen. Eritenäytteet otettiin aina ensimmäisen aamupäiväruokinnan yhteydessä aamupäivän aikana. Rehunäytteet otettiin liemirehun sekoittajasta yleensä eritenäytteiden ottopäivänä, koska emakoiden rehunvaihdokset ajoittuivat muille kuin näytteenottopäiville. Tilaseurannassa verrattiin emakoiden sontaan ja virtsaan erittyneen fosforin määrää ennen ja jälkeen rehumuutoksen. Luuston kunnon säilyminen varmistettiin analysoimalla luunäytteistä kivennäispitoisuudet ja murtolujuudet. Rehujen kivennäispitoisuudet ja fytaasiaktiivisuudet todennettiin laboratorioanalyyseillä. Emakoiden paino- ja silavamittatiedot saatiin tutkimuksen käyttöön tiineysajan lisäksi seurantatiineyden jälkeiseltä imetysajalta. Hankkeen puitteissa oli myös mahdollisuus tarkastella tilan porsastuotannon tunnuslukuja ennen ja jälkeen rehumuutoksen.

Tilaseurannan organisoiminen suurelle porsastuotantotilalle yhdessä rehu- ja lihateollisuuden kanssa vaati suunnitelmallisuutta ja organisointia kaikilta osapuolilta. Koska sikatilalla ei yleensä tarvita samaan tuotannon vaiheeseen useampaa eri rehua, erilaisia rehuseoksia voitiin testata vain peräkkäin toteutettavilla ruokintajaksoilla. Sen tekninen toteutus todettiin mahdolliseksi. Tulosten odotetaan palvelevan elinkeinon kehittämistä ympäristöystävällisempään suuntaan.

Asiasanat: sika, lanta, ympäristöriski, ruokinta 


\section{Johdanto}

\section{Sikatalouden ravinnehaasteet}

Sikatalous on suomessa keskittynyt Lounais- ja Länsi-Suomeen. Lainsäädännöllä ja tukivaatimuksilla säädetään lannan fosfori- ja typpimääristä sekä levityksestä. Ympäristönsuojelun ja etenkin vesiensuojelun tavoitteet edellyttävät ravinnekuormituksen vähentämistä. Vesistöjen tilaa voidaan parantaa, jos lantafosforia päätyy ympäristöön mahdollisimman vähän (Vanhanen ym. 2011). Tilakoko on kasvanut viimeisten 4-5 vuoden aikana, minkä seurauksena tuotannon keskittyminen on johtanut yksittäisen tilan ravinnekiertojen hallitsemisen haasteiden kasvuun. Sikatiheillä alueilla lannan levitysala ei tahdo riittää ja ympäristön liiallinen kuormitus lisää paineita lannan typen ja fosforimäärän vähentämiselle ruokinnallisin keinoin, peltoviljelyyn ja lannan käsittelyyn liittyvien toimenpiteiden lisäksi. Tätä edellytetään myös 21.2.2017 julkaistuissa BAT-päätelmissä (EU 2017).

Dourmad ym. (1999) mukaan Ranskassa 67 \% sikojen kuluttamasta typestä ja 66 \% fosforista erittyy sonnassa ja virtsassa. Heidän mukaansa pelkästään sikojen ruokintaa vaiheistamalla ravinnontarpeen mukaiseksi voidaan vähentää $15 \%$ typen ja $30 \%$ fosforin erityksestä sekä vähentää ammoniakin haihtumista ilmakehään.

\section{Raaka-aineiden fosfori ja sen käyttökelpoisuus}

Fosfori esiintyy rehuraaka-aineissa varastomuotonaan fytaattifosforina. Kasvien siemenissä ja jyvissä oleva fytiinihappo (myo-inositoliheksafosfaatti, IP6) sitoo metalli-ioneja huonosti liukenevaan muotoon eli kelatoi niitä muodostaen suoloja eli fytaatteja. Fytiinihappo muodostaa suoloja muun muassa raudan, sinkin, mangaanin, kalsiumin, kuparin ja magnesiumin kanssa, joka heikentää näiden kivennäisaineiden imeytymistä. Toisaalta fytaatteja muodostuu myös myrkyllisten metallien kuten koboltin kanssa. Koska yksimahaisilta eläimiltä puuttuu ruuansulatuksestaan fytaatteja pilkkova fytaasientsyymi, ne eivät pysty käyttämään hyväkseen fytaatti-muotoista fosforia. Kasveissa on jonkin verran luontaista fytaasia, jonka määrä vaihtelee kasvilajeittain, satokauden, olosuhteiden sekä kasvin käsittelyn mukaan. Sianrehujen raaka-aineiden valinnalla voidaan vähentää kokonaisfosforin määrää rehuseoksessa, mutta voidaan myös valita rehuraaka-aineita, jotka sisältävät runsaasti luontaista fytaasia ja vähentää näin fytaattifosforin määrää sekä lisätä rehuseoksen fosforin käyttökelpoisuutta (Partanen ym. 2010).

\section{Fosforin tarve muuttuu sioilla iän ja tuotantovaiheen mukaan}

Sikojen fosforin tarve määritetään joko tuotantokokeiden avulla tai lasketaan faktoriaalisesti ylläpitoon, tuotantoon, kasvuun, jälkeläisiin ja maidontuotantoon tarvittavan fosforin summana. Imettävän emakon fosforin tarve on huomattavasti suurempi kuin tiineen emakon, koska fosforia erittyy paljon maidossa (Taulukko 1.). Tiineiden emakoiden fosforin tarve on alhainen, jolloin rehun kokonaisfosforin määrä saattaa täyttää emakoiden tarpeen jo ilman lisättyjä rehufosfaatteja, ja varsinkin fytaasi-entsyymiä käytettäessä.

\section{Erilaisia fytaasi-entsyymejä ja niiden vaikutuksia}

Rehuihin lisätään yleisesti fytaasi-entsyymivalmisteita fosforin käyttökelpoisuuden lisäämiseksi, jolloin rehuseosten kokonaisfosforin ja erityisesti lisätyn epäorgaanisen fosforin määrää voidaan vähentää. Kaupallisia fytaasivalmisteita on lukuisia ja ne sisältävät eri mikrobeilla (mm. Aspergillus niger, Trichoderma reesei, Escherichia coli) tuotettuja fytaaseja, jotka ovat fytiinihapon fosfaattien pilkkomisen alkamiskohdan mukaan joko 3- tai 6-fytaaseja. Erityyppiset fytaasit ovat vaikutukseltaan hieman erilaisia, ja rehujen fytiinihappopitoisuus ja muut ominaisuudet vaikuttavat fytaasien kykyyn parantaa fosforin sulavuutta (Pandey ym. 2001, Pontopidan ym. 2007).

\section{Mineraalien irrottaminen luustosta}

Korkea kalsiumin ja fosforin tarve maidon tuotannon aikana aiheuttaa helposti emakoille kalsiumin ja/tai fosforin vajausta. Tämä stimuloi 1,25-dihydroksikolekalsiferolin tuotantoa, jonka pitoisuus plasmassa kasvaa maidontuotannon aikana aiheuttaen kalsiumin ja fosforin imeytymisen kasvun 
ohutsuolesta. Kalsiumia sitovan proteiinin määrä kasvaa ja suolen limakalvon fosforin läpäisevyys lisääntyy. Paratyroidihormoni säätelee mineraalien käyttöä luustosta. Kun rehun kalsiumin ja fosforin määrät ovat riittämättömät ja plasman pitoisuudet laskevat, kalsium ja fosfori otetaan luustosta. Mineraalien irrottaminen luustosta on siis riippuvaista rehun koostumuksesta (Kemme ym. 1997). Fosforin puute näkyy kuitenkin ensin tuotannon laskuna ja vasta jatkuessaan pitempään aiheuttaa luiden heikkenemistä ja katkeilua.

Imetysajan jälkeen tiineysaikana emakko ehtii tarvittaessa korjata kalsium- ja fosforivarastojaan tiineysajan rehun kalsiumin ja fosforin avulla ennen seuraavaa porsimista. Ensikolla tiineysaikainen fosforinsaanti tukee luuston mineralisoitumista kasvun yhteydessä. Jos emakon tiineysaikainen fosforinsaanti on liian matalaa, elimistö asettaa porsaiden kehityksen etusijalle ja emakon luusto luovuttaa fosforia sikiöiden hyväksi (Bikker ja Block 2017).

SiFos-hankkeessa tavoiteltiin sikojen ja siipikarjan ruokinnan kehittämisellä mm. maatilojen typpi- ja fosforierityksen minimointia. Lisäksi tavoiteltiin tilatason laskentatyökaluja, joiden avulla viljelijä voi tarkentaa tilansa ravinnekiertoa rehusta lantaan ja pellon kautta takaisin rehuun. Tässä SiFos-hankkeen osassa keskityttiin emakoiden tiineydenaikaisen fosforinerityksen vähentämisen keinoihin.

\section{Materiaalit ja menetelmät}

Tilaseuranta toteutettiin varsinaissuomalaisella porsastuotantotilalla yhteistyössä rehu- ja lihateollisuuden kanssa. Kontrollikäsittelyssä emakoiden rehustus oli tilan tavanomainen rehustus (alkutilanne), josta tehtiin alkutilanneanalyysi analysoimalla tiineiden ja imettävien emakoiden rehu-, sonta-, virtsa- ja luunäytteitä. Alkutilanneanalyysiä varten yhteensä satunnaisesti valitulta 166 emakolta otettiin sonta- ja virtsanäytteitä tiineyden päivinä n. 30, 90 ja 103-114. Lisäksi noin 100 teuraaksi menneestä emakosta kerättiin luunäytteitä analysoitavaksi ennen ja jälkeen rehumuutoksen. Mahdollisimman monelta emakolta kerättiin molemmat, sekä sonta- että virtsanäytteet.

Koekäsittelyssä porsastuotantotilan kaikkien pois lukien ensikot, tiineiden emakoiden rehun kokonaisfosforipitoisuutta alennettiin, alkutiineyden rehun kokonaisfosforipitoisuus aleni $23 \%$ ja lopputiineyden $22 \%$. Eläinten riittävästä fosforinsaannista huolehdittiin siten, että rehujen sulavan fosforin laskennallinen pitoisuus pidettiin riittävän korkeana ja fosforin hyväksikäyttö varmistettiin oikealla fytaasientsyymiannoksella, joka ei kuitenkaan muuttunut kontrolli- ja koekäsittelyjen välillä. Entsyymin tarkoitus on irrottaa rehuaineiden fytaattifosforia sian elimistön käyttöön.

Koekäsittelyssä seurantaan valittujen 52 emakon tiineyden aikana niiltä kerättiin sonta- ja virtsanäytteet alkuanalyysiin verrattuna samoina tiineyden päivinä n. 30, 90 ja 103-114 tilan tuotantorytmiin sovittaen. Sonta- ja virtsanäytteet otettiin aina ensimmäisen aamupäiväruokinnan yhteydessä aamupäivän aikana. Rehunäytteet otettiin liemirehun sekoittajasta yleensä sonta- ja virtsanäytteiden ottopäivänä, koska emakoiden rehunvaihdokset ajoittuivat muille kuin näytteenottopäiville.

Tilaseurannassa verrattiin emakoiden sontaan ja virtsaan erittyneen fosforin määrää ennen ja jälkeen rehumuutoksen. Luuston kunnon säilyminen varmistettiin analysoimalla rehumuutosta ennen ja sen jälkeen teuraaksi menneiden emakoiden luunäytteistä kivennäispitoisuudet ja murtolujuudet. Rehujen kivennäispitoisuudet ja fytaasiaktiivisuudet todennettiin laboratorioanalyyseillä. Emakoiden paino- ja silavamittatiedot saatiin tutkimuksen käyttöön tiineysajan lisäksi seurantatiineyden jälkeiseltä imetysajalta. Hankkeen puitteissa oli myös mahdollisuus tarkastella tilan porsastuotannon tunnuslukuja ennen rehumuutosta ja sen jälkeen.

\section{Tulokset ja tulosten tarkastelu}

Alkuanalyysissä teuraaksi menneiden emakoiden etusorkan sormiluiden $\mathrm{Ca}, \mathrm{P} \mathrm{ja} \mathrm{Mg}$-pitoisuudet olivat 449, 199 ja 5,6 $\mathrm{g} \mathrm{kg}^{-1} \mathrm{ka}$. Seurantaemakoiden painon alenema imetysaikana ei eronnut tilan tavanomaisesta tuloksesta. Pitkän aikavälin vaikutuksia emakoiden porsastuotantoparametreihin ei 
voida raportoida näin lyhyen seurantajakson perusteella, mutta porsastuotantotilalla matalamman kokonaisfosforipitoisuuden tiineysrehujen syöttäminen emakoille jatkuu edelleen, joten mahdollisista muutoksista emakoiden porsastuotantoparametreissa voidaan saada tietoa myöhemmin. Tämän seurantajakson aikana kerättyjen tietojen ja näytteiden laajempi analyysi julkistetaan vuoden 2020 aikana myöhemmin päätettävällä kansallisella foorumilla.

Säännöllinen kommunikaatio seurantatilan, rehu-, lihateollisuus- ja tutkimusosapuolten välillä on välttämätöntä. Osapuolten joustavuutta tarvitaan, jotta kullekin osapuolelle sopiva ajankohta tilaseurannan toteuttamiseksi löytyy ja seuranta (ainutlaatuinen 3-vuotisen hankkeen aikana) saadaan toteutettua suunnitellusti.

Taulukko 1. Tiineiden ja imettävien emakoiden sulavan fosforin tarve (g sulP MJ-1 NE), kalsiumin (Ca) ja fosforin (P) suhde rehussa ja D-vitamiinin tarve (National Research Council 2012, Luke 2018, Tybrik ym. 2019)

\begin{tabular}{lcccc}
\hline g sulP MJ NE & Tiineet & Imettävät & Ca:P & $\begin{array}{c}\text { D-vitamiini } \\
\text { IU kg-1 }\end{array}$ \\
\hline Suomi & 0.28 & 0.34 & $2.5-3.1$ & $790 / 980$ \\
Tanska & 0.22 & 0.33 & $2.3(-2.6)-(3.0-) 3.5$ & 800 \\
& & & & 800 \\
National Research Council & $0.20-0.35$ & $0.30-0.40$ & & 800 \\
\hline
\end{tabular}

\section{Johtopäätökset}

Tilaseurannan organisoiminen suurelle porsastuotantotilalle yhdessä rehu- ja lihateollisuuden kanssa vaati suunnitelmallisuutta ja organisointia kaikilta osapuolilta. Koska sikatilalla ei yleensä tarvita samaan tuotannon vaiheeseen useampaa eri rehua, erilaisia rehuseoksia voitiin testata vain peräkkäin toteutettavilla ruokintajaksoilla. Sen tekninen toteutus todettiin mahdolliseksi. Tulosten odotetaan palvelevan elinkeinon kehittämistä ympäristöystävällisempään suuntaan.

\section{Kiitokset}

SiFos-hanketta ovat rahoittaneet Euroopan maatalouden kehittämisen maatalousrahasto, Hankkija Oy, A-Rehu Oy, Kollin Säätiö, MTK ry., Suomen Sianjalostuksen säätiö ja Suomen Siipikarjasäätiö ja toteutukseen on osallistunut Heikkilän tila. Kiitämme hankkeen rahoittajia ja toteutukseen osallistuneita hankkeen tukemisesta ja toimintaan osallistumisesta. Kiitokset myös Luken tekniselle henkilöstölle työpanoksesta kumppanuustila-aineistojen käsittelyssä.

\section{Kirjallisuus}

Bikker, P. \& Blok, M.C. 2017. Phosphorus and calcium requirements of growing pigs and sows. CVB Documentation Report nr. 59. 74 s. Viitattu 7.2.2020. https://library.wur.nl/WebQuery/wurpubs/527741

Dourmad, J.Y., Guingand, N., Latimier, P. \& Sève, B. 1999. Nitrogen and phosphorus consumption, utilization and losses in pig production: France. 1999. Livestock Production Science 58: 199-211. https://doi.org/10.1016/S0301-6226(99)00009-3

EU 2017. Komission täytäntöönpanopäätös 2017/302. Euroopan unionin virallinen lehti, L 43: 231-279. 
Vanhanen, M., Haaranen, T., Heilä, J., Herlin, I., Ikävalko, J., Jantunen, A., Kulmala A., Hakanen, M., Koljonen, M., Lähteenmäki, S., Madekivi, O., Toivikko, S., Turtola, E., Vilhunen, S., Wallenius, S., Marttinen, S. \& Bruun, A. 2011. Suomesta ravinteiden kierrätyksen mallimaa. Työryhmäraportti. 66 s. Viitattu 7.2.2020. https://mmm.fi/documents/1410837/1724539/trm2011_5.pdf.

Kemme, P.A., Radcliffe, J.S., Jongbloed, A.W. \& Mroz, Z. 1997. The effects of sow parity on digestibility of proximate components and minerals during lactation as influenced by diet and microbial phytase supplementation. Journal of Animal Science 75: 2147-2153. https://doi.org/10.2527/1997.7582147x

Luke 2018. Rehutaulukot ja ruokintasuositukset. Luonnonvarakeskus. Viitattu 7.2.2020. http://www.luke.fi/rehutaulukot.

National Research Council 2012. Nutrient Requirements of Swine: Eleventh Revised Edition. Washington, DC. The National Academies Press. 420 s.

Pandey, A., Szakacs, G., Soccol, C. R., Rodirguez-Leon, J.A. \& Soccol, V.T. 2001. Production, purification and properties of microbial phytases. Bioresource Technology 77: 203-214. https://doi.org/10.1016/S09608524(00)00139-5

Partanen, K., Karhapää, M., Voutila, L. \& Ylivainio, K. 2010. Ruokinnan keinot sianlannan fosforipitoisuuden alentamiseksi. Suomen Maataloustieteellisen Seuran Tiedote 26. https://doi.org/10.33354/smst.75698

Pontopiddan, K., Pettersson, D. \& Sandberg, A.-S. 2007. Peniophora lycii phytase is stable and degrades phytate and solubilizes minerals in vitro during simulation of gastrointestinal digestion in the pig. Journal of the Science of food and Agriculture 87: 2700-2708. https://doi.org/10.1002/jsfa.3033

Tybirk, P, Sloth, N.M., Kjeldsen, N. \& Vinther, J. 2019. Normer for Næringsstoffer. Videncenter for Svineproduktion. Denmark. 